\title{
Analyzing the Resilience of the Employee Network in Joint-equity Commercial Banks
}

\author{
Shuliang Lv, Chuanchao Huang and Lanying Du* \\ School of Management, Huazhong University of Science and Technology, Wuhan \\ 430074, China \\ *lanyingdu@163.com
}

\begin{abstract}
In recent years, organizational resilience has been a hot topic in the field of management. The network consisting of employees in a company is a typical organization. The resilience of such employee networks is quite important for the company to be efficiently operated. For the situation of employee turnover and loss in joint-stock commercial banks, in this paper we define the risk as the number of employees leaving the company and examine the resilience of the employee network from three aspects: assimilation, adaptation and recovery. A computational model is constructed based on the process of "damage-assimilation-adaptation-recovery" for the employee network. Moreover, we compare the resilience for two different network structures belonging to complex networks: the small-world network and the scale-free network. Other factors including the communication among employees and the role of each employee are also taken into account. Our results show that the small-world network has remarkable advantages in assimilation and adaptation under the small scale of risk, while the scale-free network has stronger ability of recovery and higher resilience than the former. The employee networks with scale-free property may not be benefitted from protecting core employees.
\end{abstract}

Keywords: resilient model; complex network; social network; simulation

\section{Introduction}

Over the past twenty years, the number of financial companies increases at an unprecedented rate. Those companies face many different challenges [1]. Apart from the external factors like the technical change and the competitive market environment [2], there are also many internal threats. One of the significant internal threats is the high demission rate [3], which has a great impact on the efficiency of a company. When a lot of employees leave, some companies can recover quickly while others cannot or even close down. The resilience of the organization consisting of employees becomes quite important. We treat each employee as a node, and then all employees form a network, which is named as the employee network. We will analyze the resilience of the employee network in this paper.

Under the shock from internet finance, employee network in joint-equity commercial banks has been the hot topic for its unpredictability and dynamic changes. Therefore, the employee network is a kind of the social network which has been widely studied $[5,26]$. The social network is considered to be formed by employees who gather together to share their knowledge and experience based on information relationship. It has been found that the diversity and density of the social network play significant roles in promoting organizational performance [6], and the non-centralization structure of network can achieve higher performance than the centralized structure [7]. 
The managers of companies have invested large amount of capital to improve their operating efficiency. They mainly put efforts to improve the culture of the enterprise and the working atmosphere, but the structure of the employee network is ignored [4,27]. With the high demission rate, the employee network can be destroyed such that the company cannot be well operated. Traditional organization theories cannot solve such complex problems in social networks [9]. In this paper we try to quantitatively calculate the resilience of the employ network and analyze the factors related to the resilience.

The remainder of this paper is organized as follows. In Section 2, we provide an introduction to the organizational resilience and its combination with social networks. In Section 3 the resilient model for the employee network is constructed. Section 4 shows the simulation results, and the last section summarizes this study and describes the future research.

\section{Literature Review}

"Resilience" is initially used to represent the ability to restore the original position or state. Holling [8] introduced this concept in the social ecology in 1973 to explain the absorptive and adaptive ability. In recent years, there has been a growing interest in the field of organizational resilience in enterprise management. The organizational resilience in this paper refers to the resilience of network consisting of employees in a company. From the perspective of human resource management, individual cognitive ability and subjective initiative could be the core of organizational resilience [10]. The work in [11] introduces the quantitative approach for the relationship between resilience and time.

The network resilience has attracted much attention of physicists working in the file of complex networks during the past few years [12]. In complex networks, individuals are abstracted as nodes, and their social relations are links among nodes. Many dynamic models has been proposed to analyze how the network structure and characteristic influence the network resilience [13, 14]. Those models relax the assumption of the interaction among individuals, which can reveal the dynamic evolution of the network [15].

In the employee network, each individual's behavior affects the resilience. Many works have studied the impacts of individual's choice on the network [16, 17]. Moreover, in an economic context, for instance, it is well known that small cliques of core employees can form a niche [18]. This phenomenon highlights one fundamental questions in network dynamics, that what strategy the managers adopt to administrate the core employees to improve the resilience of the employee network. This will also be analyzed in our work.

\section{The Resilience of the Employee Network}

In this paper each employee is a node in the network and the risk is defined as the number of removed nodes. Figure 1 provides an example illustrating networks before and after the risk.
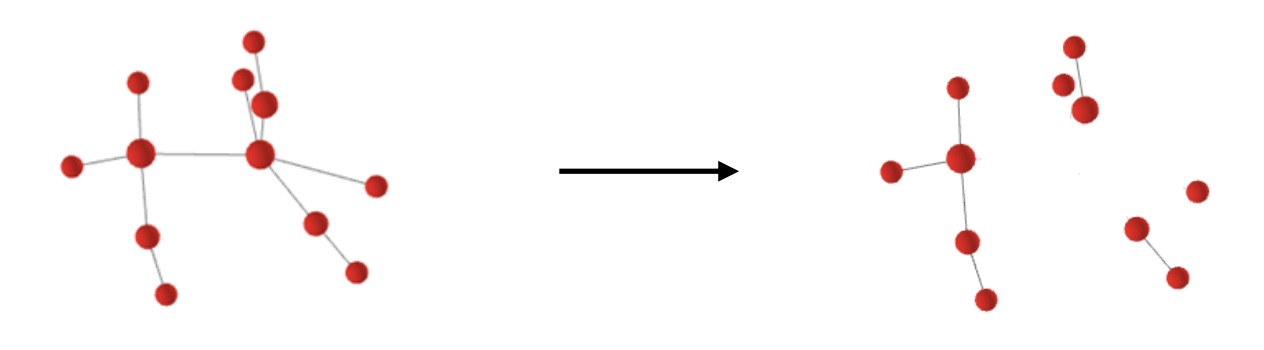

Figure 1. An Example Showing Networks Before and After the Risk 
In a company, promoting communications among employees can enhance the resilience of the network. We introduce two different modes of communications: the mode of preferring core employee (represented by A1) and the mode of non-preference mode (represented by A2). The importance of an employee is measured by its degree in the network. Thus the core employee is the node with the high degree. In A1, when the company meets the risk, core employees are prior to others to get resources and establish new connections. In A2, each employee has the same probability to establish connections with other individuals. Due to the limitation of resources, this mode is manifested as stochastic resource distribution in the employee network.

Suppose that there are $N$ employees in a joint-stock commercial bank, in order to effectively allocate resources and maximize efficiency, resources are distributed based on the two modes which are represented by $A 1=\left(a_{1}, \ldots, a_{k}, \ldots a_{N}\right)$ and $A 2=(a, \ldots, a, \ldots a)$. ak represents the degree of node $\mathrm{k}$ in the network and $\mathrm{a}$ is a constant. In mode $\mathrm{A} 1$, the communication factors are distributed based on the degree of nodes while in A2 communication factors are distributed randomly.

In addition, we introduce the intensity of interactions $\mu$ which affects the effectiveness of communication factors. For example, employee i obtains two communication factors, he/she will have the probability $0.2 * \mu$ to build relationship with neighbors.

The resilience of the employee network can be characterized by the following three aspects.

- Assimilation. When some accidents happen, the employee network can still keep its functionality. It not only is beneficial to the development of companies but also protects them from emergencies [19].

- Adaptation. A social network with high resilience should be able to adjust itself to deal with accidents. The better the adaptation ability, the stronger the resilience is [20].

- Recovery. Recovery is an inherent property of the employee network. When the employee network is destroyed by some accidents, it has the ability of self-healing.

Figure 2 shows the variation of the efficiency of the employee network with the time [21]. In the figure, $\mathrm{F}$ represents the network efficiency of the employee network. When $\mathrm{t}=\mathrm{t} 0$, the accident happens and the network efficiency begins to decrease. The assimilation and adaptation are reflected by the decreased amount. From t0 to t1, the assimilation helps to reduce the loss of the network efficiency, and the adaptation helps to increase the reliability of the network. From $\mathrm{t} 1$ to $\mathrm{t} 2$, the employee network rebuilds its structure and adjusts itself to restore.

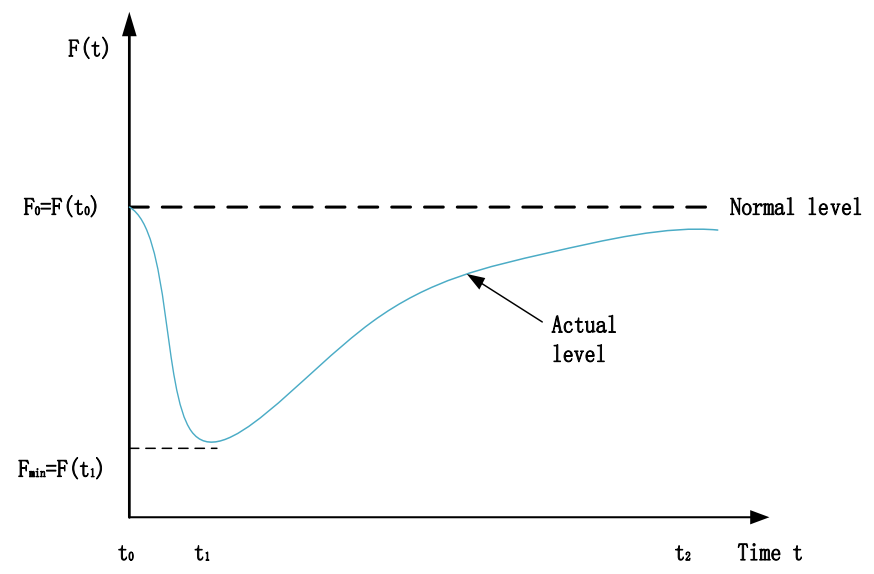

Figure 2. The Conceptual Design of the RSN Model 
The network efficiency of the employee network is expressed as Eq.(1), where $G$ is the set of nodes, $N$ is the number of nodes in the network, $N_{e}$ is the number of links in the network, $d_{i j}$ is the number of nodes in the shortest path connecting node $i$ and node $j, c_{i j}$ represents the influence of individual $i$ to individual $j$, and $c_{i j}=\alpha_{i} / \alpha_{j^{*}} \mu$, $\mu$ is the intensity of interactions among individuals. The incentive parameter $\alpha$, which is related to traits of individual, such as personality and the degree of the nodes, and $\alpha$ obeys normal distribution $(0,1)$.

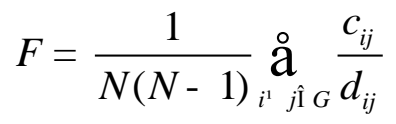

As mentioned above, the assimilation and adaptation ability are reflected by the difference between $F_{0}$ to $F_{\min }$, which is expressed in Eq.(2).

$F_{c}=F_{0}-F_{\text {min }}$

The recovery time $T_{c}$ is expressed in Eq.(3), which is used to measure the recovery ability.

$T_{c}=t_{2}-t_{1}$

According to [15], the resilience of the social network can be defined in Eq.(4).

$R=\frac{F\left(t_{2}\right)-F\left(t_{1}\right)}{t_{2}-t_{1}}$

The variation of the resilience of the employee network under the risk can be simulated through the following steps.

Step1: Given the scale of the risk, the nodes in the employee network are removed randomly.

Step2: Employees in the network schedule resources to absorb and adapt to the risk.

Step3: Enterprise takes different models to stimulate employees to recover the networks.

Step4: Repeat step 3, until the network efficiency is no longer changed.

\section{Simulation Results}

Base on the data of employee turnover rate from a commercial bank in Zhengzhou in China, we carry out simulation experiments based on the proposed model. We consider each employee in a company as a node, and all nodes form a network. We assume there are two different types of networks: small-world networks and scale-free networks. The parameters of the simulation are summarized in Table 1. The risking scale is represented by the number of removed nodes in the network. We consider two different risking scales: $5 \%$ and $10 \%$.

We stop a simulation until the network efficiency reaches stabilizations or 100 steps are passed. All simulations are averaged over 100 runs.

Table 1. The Parameters in the Simulation

\begin{tabular}{|c|c|}
\hline Parameter & Value \\
\hline the number of nodes & 120 \\
\hline maximum simulation steps & 100 \\
\hline $\begin{array}{c}\text { intensity of interactions } \mu \\
\text { risking scale, } b\end{array}$ & $\begin{array}{c}0.4 \\
\text { and } 10 \%\end{array}$ \\
\hline
\end{tabular}




\subsection{Analysis of the Three Abilities}

Figure 3 illustrates the relation between $F_{c}$ and $\mu$ for the two different risking scales. From Figure 3a, we can see that the small-world network has stronger assimilation ability than the scale-free network. However, for the large risking scale, i.e., $b=10 \%$, the scale-free network is more robust than the small-world network. This is consistent with the results in [22-24]. Therefore, we can conclude that the company in which the employees are formed as a scale-free network has a good ability to resist the high demission rate.

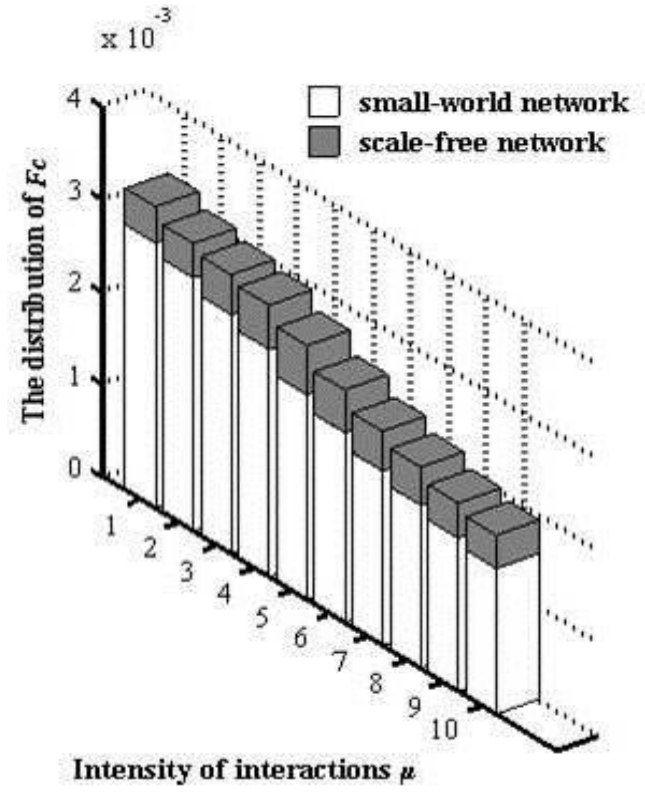

(a) Small Risking Scale (5\%)

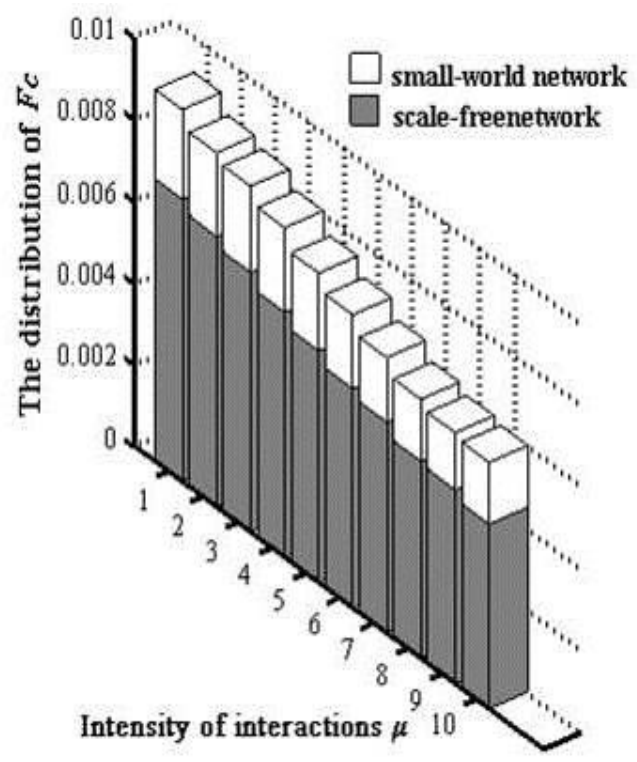

(b) Large Risking Scale (10\%)

Figure 3. $F_{\mathrm{c}}$ vs $\boldsymbol{\mu}$ Under Different Risking Scales

To investigate the adaptation ability of the two different types of networks, we vary the value of $b$, the corresponding values of $F c$ are plotted in Figure 4 . As we can see, for small risking scales, i.e., $\mathrm{b}<=8 \%$, the small-world network has better adaptability while for large risking scales, i.e., $b>=8 \%$, the scale-free network performs better in terms of the adaptability.

In addition, in the scale-free network, unless key nodes are removed, the network always has good resilience. For the company with high demission rate, it is better to organize the employees as the scale-free network and prevent the core employees leaving. For the traditional company with small demission rate, it is better to organize the employees as the small-word network.

Further we analyze the recovery ability of the employee network under mode A1 and mode A2. The risking scale b is set to be 5\%. As we can see, the network with the small-world property has better recovery ability in A1 than in A2. This is because nodes in small-world networks are scattered, that is, individuals with small degrees can establish relationships with core employees in A1, which will improve the network resilience. In mode A2, ordinary employees are hard to make full use of resources due to the inherent property of the small-world network. Interestingly, the opposite phenomenon is observed in Table 3 for scale-free networks. This is because establishing links is not only related to the intensity of interactions but also related to the physical distance [21]. For example, in joint-stock commercial Banks, to maintain the high efficiency of the major indexes, the core staffs are always the key in the employee network. 


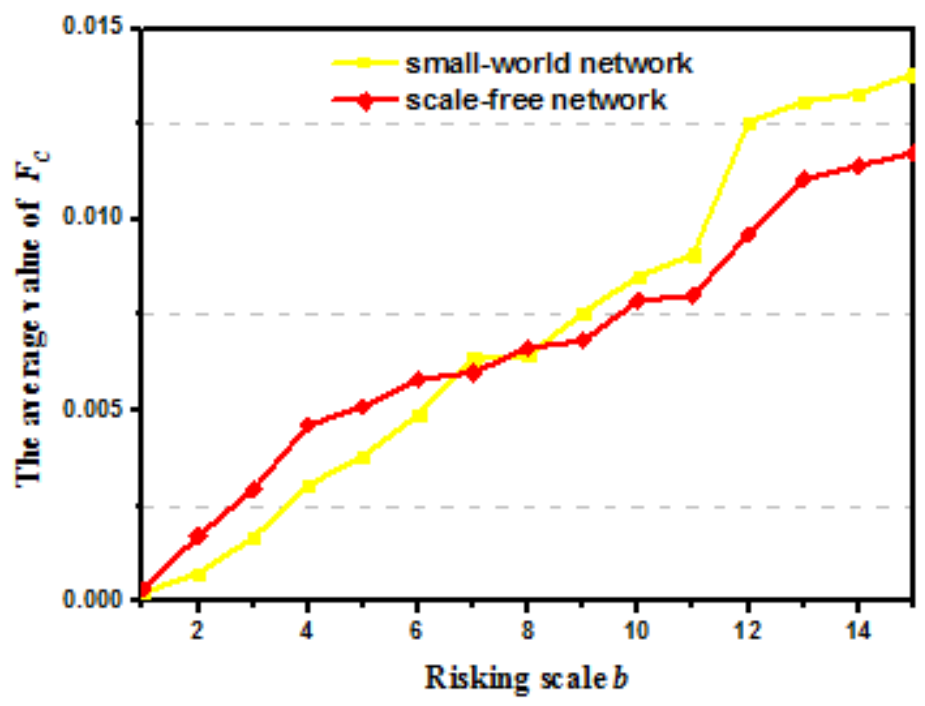

Figure 4. The Difference Value $\boldsymbol{F}_{c}$ vs the Risking Scale $b$.

Table 2. The Average Value of Recovery Time $T_{\mathrm{c}}$ in the Small-World Network

\begin{tabular}{|c|c|c|c|c|c|c|c|c|c|c|}
\hline \multirow{2}{*}{ Recovery time $\boldsymbol{T}_{\boldsymbol{c}}$} & \multicolumn{10}{|c|}{ Intensity of interactions $\boldsymbol{\mu}$} \\
\cline { 2 - 11 } & $\mathbf{0 . 1}$ & $\mathbf{0 . 2}$ & $\mathbf{0 . 3}$ & $\mathbf{0 . 4}$ & $\mathbf{0 . 5}$ & $\mathbf{0 . 6}$ & $\mathbf{0 . 7}$ & $\mathbf{0 . 8}$ & $\mathbf{0 . 9}$ & $\mathbf{1 . 0}$ \\
\hline$A_{l}$ & 31.47 & 17.55 & 8.23 & 5.74 & 4.01 & 3.64 & 3.43 & 3.15 & 2.96 & 2.56 \\
\hline$A_{2}$ & 32.85 & 18.33 & 10.17 & 6.35 & 5.56 & 5.12 & 4.72 & 4.38 & 3.45 & 2.97 \\
\hline
\end{tabular}

Table 3. The Average Value of Recovery Time $T_{c}$ in the Scale-Free Network

\begin{tabular}{|c|c|c|c|c|c|c|c|c|c|c|}
\hline \multirow{2}{*}{ Recovery time $\boldsymbol{T}_{\boldsymbol{c}}$} & \multicolumn{10}{|c|}{ Intensity of interactions $\boldsymbol{\mu}$} \\
\cline { 2 - 12 } & $\mathbf{0 . 1}$ & $\mathbf{0 . 2}$ & $\mathbf{0 . 3}$ & $\mathbf{0 . 4}$ & $\mathbf{0 . 5}$ & $\mathbf{0 . 6}$ & $\mathbf{0 . 7}$ & $\mathbf{0 . 8}$ & $\mathbf{0 . 9}$ & $\mathbf{1 . 0}$ \\
\hline$A_{1}$ & 31.35 & 17.04 & 9.44 & 5.78 & 4.90 & 4.34 & 3.88 & 3.03 & 2.55 & 2.32 \\
\hline$A_{2}$ & 30.23 & 15.14 & 8.01 & 5.22 & 3.67 & 3.12 & 2.77 & 2.35 & 2.14 & 1.98 \\
\hline
\end{tabular}

\subsection{Resilience of the Employee Network}

Through the above analysis, we can find that small-world networks has better assimilation and adaptation abilities, but worse recovery ability than scale-free networks. In this part, we are trying to answer these questions: what is the relationship among the three abilities; which ability is the most important one for the resilience; what is the relationship between the communication factor and the intensity of interactions.

We draw Figure 5a and Figure 5b to illustrate the relation of the resilience of the employee network with the communication factor and the intensity of interactions. The mode A1 is assumed. As we can see, the scale-free network has a better resilience than the small-world network. Compared with the results in Table 2 and Table 3, we can conclude that the recovery ability is more important than the other two abilities for the resilience. We can also see that the intensity of interactions has larger effects than the communication factor. That is to say, it is beneficial to strengthen the interactions among employees. 


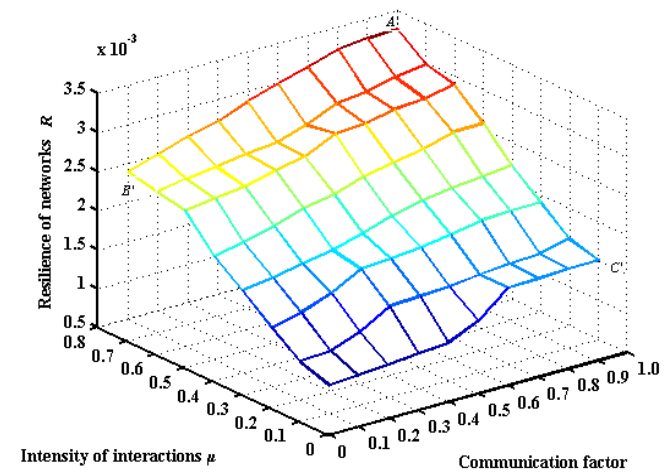

(a) Resilience of the Small-World Network

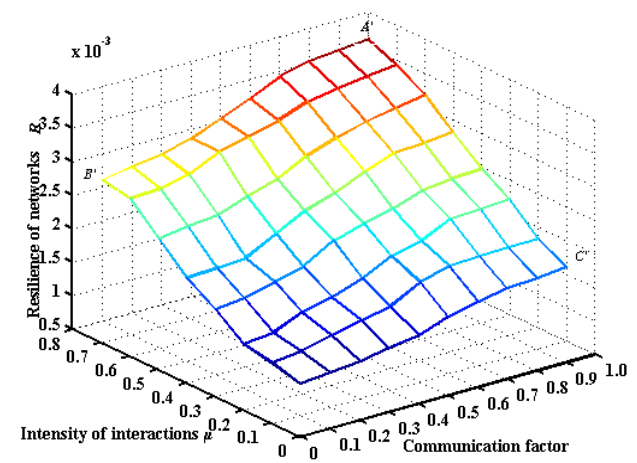

(b) Resiliece of the Scale-Free Network

\section{Figure 5. Resilience of Two Kinds of Networks Under Mode $A_{1}$}

For the mode $A_{2}$, we take the scale-free network as an example and the results are shown in Figure 6. We find that the intensity of interactions and the communication factor have almost the same impact on the resilience, thus the manager of the company should seek a balance between the two factors. We can also see that the resilience in Figure 6 is bigger than that in Figure 5b, which shows the benefits of mode $A_{2}$. Lengnick-Hall [30] ever pointed out that the nodes with high degree in a network are critical for the resilience of the network. However, our study shows that the employee network with scale-free property may not be benefitted from protecting core employees.

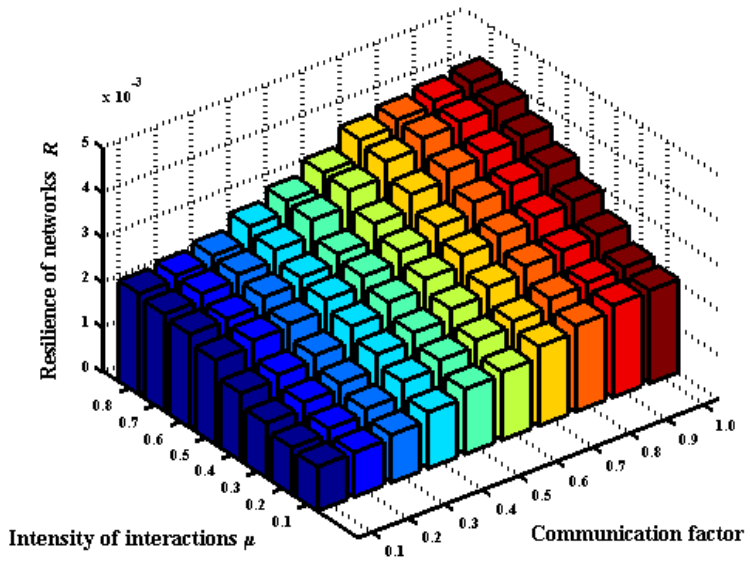

Figure 6. Resilience of Scale-Free Network in $A_{2}$

Besides, the resilience in Figure 6 is clearly bigger than Figure 5b, and it shows the good performance in $A_{2}$. Lengnick-Hall et al deemed that core employees can help organization to contribute to pulling through, and it is critical to protect core employees in facing up to risks [25]. However, our study manifests that the social networks with scale-free property may not be benefitted from protecting core employees. 


\section{Conclusions}

Faced with complicated competitive environments, the demission rate is quite high for many companies, which can lower their operating efficiency and damage the network consisting of employees. In this paper we study the factors related to the resilience of the employee network in joint-equity commercial banks, revealing the process of an employee network suffering the risk, i.e., "damage-assimilation adaptation-recovery". We built the computational model for the resilience based on this process. The main findings are listed below.

1) The small-world network is superior to the scale-free network when the scale of risk is small. The scale-free network is able to resist large scale of risks, which is a good option for internet enterprises.

2) The recovery ability is the dominate ability for the resilience, and it performs differently in the two structures of networks.

3) Core employees play important roles in small-world networks, but they have little impact on the scale-free network, which means that the employee network with scale-free property may not be benefitted from protecting core employees.

In a word, our study built the computational model of resilience, and investigated the assimilation, adaptive and recovery abilities of resilience, which could provide references for the management of companies. However, there still are some more complex phenomena which have not been considered in this research. For example, psychological changes of employees are not taken into consideration. In future work, we will study the probability of risks and more network structures. We hope that this paper will contribute to further quantitative studies in resilience.

\section{References}

[1] Ettredge M L, Richardson V J. Information transfer among internet firms: the case of hacker attacks. Journal of Information Systems, 2003, vol. 17, no. 2, pp. 71-82.

[2] Rothaermel F T, Kotha S, Steensma H K. International market entry by US internet firms: an empirical analysis of country risk, national culture, and market size. Journal of Management, 2006, vol. 32, no. 1, pp. 56-82.

[3] Baron J N, Hannan M T, Burton M D. Labor Pains: Change in Organizational Models and Employee Turnover in Young, High - Tech Firms1. American Journal of Sociology, 2001, vol. 106, no. 4, pp. 960-1012.

[4] J H Gittell, K. Cameron, S. Lim, et al. Relationships, layoffs, and organizational resilience airline industry responses to September 11. The Journal of Applied Behavioral Science, 2006, vol. 42, no. 3, pp. 300-329.

[5] Lesser E, Prusak L. Communities of practice, social capital and organizational knowledge. Information Systems Review, 1999, vol. 1, no. 1, pp. 3-9.

[6] Reagans R, Zuckerman E W. Networks, diversity, and productivity: The social capital of corporate R\&D teams. Organization science, 2001, vol. 12, no. 4, pp. 502-517.

[7] Rulke D L, Galaskiewicz J. Distribution of knowledge, group network structure, and group performance. Management Science, 2000, vol. 46, no. 5, pp. 612-625.

[8] Holling C S. Resilience and stability of ecological systems. Annual review of ecology and systematics, 1973: 1-23.

[9] Sutcliffe K M, Vogus T J. Organizing for resilience. Positive organizational scholarship: Foundations of a new discipline, 2003, 94: 110.

[10] Lengnick-Hall C A, Beck T E, Lengnick-Hall M L. Developing a capacity for organizational resilience through strategic human resource management. Human Resource Management Review, 2011, vol. 21, no. 3, pp. 243-255.

[11] Henry D, Emmanuel Ramirez-Marquez J. Generic metrics and quantitative approaches for system resilience as a function of time. Reliability Engineering \& System Safety, 2012, 99, pp. 114-122.

[12] Cohen R,Erez K,Ben-Avraham D,et al.Resilience of the Internet to random breakdowns.Physical review letters, 2000, 85(21): 4626.

[13] Adger $\mathrm{W}$ N,Hughes $\mathrm{T}$ P, Folke C, et al.Social-ecological resilience to coastal disasters.Science, 2005,309(5737) pp. 1036-1039.

[14] Ash J, Newth D.Optimizing complex networks for resilience against cascading failure.Physica A:Statistical Mechanics and its Applications,2007,380: 673-683. 
[15] Goldspink C, Kay† R. Organizations as self-organizing and sustaining systems: a complex and autopoietic systems perspective. International Journal of General Systems, 2003, 32(5): 459-474.

[16] Joseph J. Resilience as embedded neoliberalism: a governmentality approach. Resilience, 2013, 1(1): pp. $38-52$.

[17] Kwon K H, Stefanone M A, Barnett G A. Social network influence on online behavioral choices exploring group formation on social network sites. American Behavioral Scientist, 2014, 58(10): 13451360.

[18] Chris A. The long tail: Why the future of business is selling less of more. 2006.

[19] Cyert R M, March J G. A behavioral theory of the firm. Englewood Cliffs, NJ, 1963, 2.

[20] Pulley M L. Beyond the leader: Building organizational Resiliency. American Banker Magazine, 2004: 14.

[21] Chen L, Gable G G, Hu H. Communication and organizational social networks: a simulation model[J]. Computational and Mathematical Organization Theory, 2013, 19(4): 460-479.

[22] Newman M E J. Mixing patterns in networks. Physical Review E, 2003, 67(2): 026126.

[23] D S Callaway, M E J Newman, Strogatz S H, et al. Network robustness and fragility: Percolation on random graphs. Physical review letters, 2000, vol. 85, no. 25, 5468.

[24] Holme P, Kim B J, Yoon C N, et al. Attack vulnerability of complex networks. Physical Review E, 2002, vol. 65 , no. 5, 056109 .

[25] Lengnick-Hall C A, Beck T E, Lengnick-Hall M L. Developing a capacity for organizational resilience through strategic human resource management. Human Resource Management Review, 2011, vol. 21, no. 3, pp. 243-255.

[26] Z Hou, H Bin, W Jiang, et al. "Adaptation of cultural norms after merger and acquisition based on the heterogeneous agent-based relative-agreement model", Simulation: Transactions of the Society for Modeling and Simulation International, (2013), vol. no. 89(2), pp. 1523-1537.

[27] W Haining, J Björn, L Xueshan, et al. "Realization of Enterprise Architecture (EA) Benefits: A Meta Study on Control and Controllability", Practice-Driven Research on Enterprise Transformation, (2013), pp 92-105. 
International Journal of Security and Its Application Vol.11, No.1 (2017) 